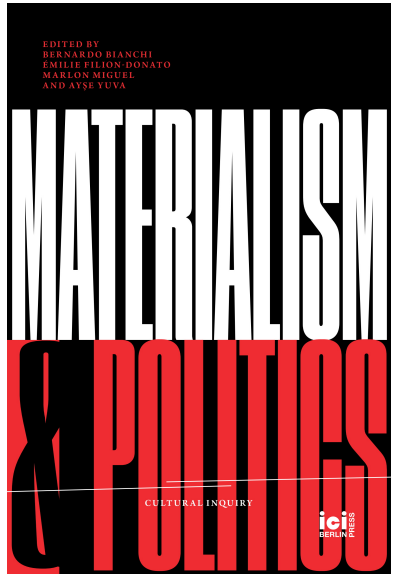

Materialism and Politics, ed. by Bernardo $\mathrm{Bi}$ anchi, Emilie Filion-Donato, Marlon Miguel, and Ayşe Yuva, Cultural Inquiry, 20 (Berlin: ICI Berlin Press, 2021), pp. 253-68

\section{CHRISTOPH F. E. HOLZHEY (iD}

\section{Emergence that Matters and Emergent Irrelevance \\ On the Political Use of Fundamental Physics}

CITE AS

Christoph F. E. Holzhey, 'Emergence that Matters and Emergent Irrelevance: On the Political Use of Fundamental Physics', in Materialism and Politics, ed. by Bernardo Bianchi, Emilie FilionDonato, Marlon Miguel, and Ayşe Yuva, Cultural Inquiry, 20 (Berlin: ICI Berlin Press, 2021), pp. 253-68<https://doi.org/10. 37050/ci-20_14>

\section{RIGHTS STATEMENT:}

(C) by the author(s)

Except for images or otherwise noted, this publication is licensed under a Creative Commons Attribution-ShareAlike 4.0 International License.

ABSTRACT: With reference to the mobilization of physics in new feminist materialisms, this chapter argues that the fundamental ontology of matter suggested by physics is of no political relevance. Instead, its position is that devising effective strategies to deactivate the normative power of fundamental ontologies remains politically relevant despite long-standing critiques of essentialism. The chapter proposes that physics can be helpful both for understanding its own irrelevance and for inspiring strategies of deactivation.

KEYWORDS: new feminist materialisms; ontological turn; normativity; emergence; scale; thermodynamics; physics; matter; performativity (philosophy); Barad, Karen 


\title{
Emergence that Matters and Emergent Irrelevance
}

\author{
On the Political Use of Fundamental Physics
}

CHRISTOPH F. E. HOLZHEY

Physics was long considered as the model science. It arguably lost this role to the life sciences towards the end of the twentieth century, but some strands of new materialism have helped to give it a second wind. How physics theorizes matter seems to matter again, and not only intellectually but politically as well. As an ex-physicist who is semi-converted to the humanities, I am quite interested in the idea of mobilizing the critical potential of physics, but for this very reason I find it important to problematize some of the ways in which this potential tends to be all too quickly either embraced or rejected.

In this chapter, I will need to be quite quick and schematic myself and will only give some indications and elaborations on three points. They are, firstly, my claim that the fundamental ontology of matter has no political relevance; secondly, my position that what is politically relevant is, instead, to devise effective strategies to deactivate the normative power of fundamental ontologies; and thirdly, the proposition that physics can be helpful to address these first two points, that is, to understand its own irrelevance and at the same time inspire strategies to deactivate the normativity of ontologies of matter. 


\section{THE FUNDAMENTAL ONTOLOGY OF MATTER IS (POLITICALLY) IRRELEVANT}

Let me begin with some clarifications of my claim. I speak of the 'fundamental ontology of matter' and take it primarily in the sense that one might associate with physics, that is, in terms of defining elementary material constituents and establishing their laws of interaction, or what is often referred to as the 'theory of everything.' primarily mean by the term 'ontology' even when I do not qualify it further; I do not thereby intend to subsume or exclude other dimensions or meanings of ontology, in particular not a 'materialist ontology', which I would consider to have a far broader meaning.

By claiming that the ontology of matter has no relevance, I mean that no difference could be detected on our human scale - or indeed any finite length scale - if the fundamental ontology were quite radically different. I am thinking of alternatives such as discrete particles moving in a vacuum vs a continuum conception of matter; or processes fully determined by laws of motion (which is associated with mechanics) vs allowing for random deviations or something like free will.

My claim, then, is that any of these ontological options are compatible with all that could possibly matter on any specified scale. When it is understood in this way my claim could seem unsurprising. Who would have thought that the ontologies of matter proposed by physics are politically relevant? Wouldn't that imply, among other things, an archaic appeal to nature, falling prey to the naturalistic fallacy of de-

1 See, e.g., the glossary of Brian Greene, The Elegant Universe: Superstrings, Hidden Dimensions, and the Quest for the Ultimate Theory (New York: Vintage Books, 2000): 'T.O.E. (Theory of Everything). A quantum-mechanical theory that encompasses all forces and all matter' (p. 423). The term became popular in the 1980s in the context of string theory as a promising candidate to address the fundamental incompatibility of highly successful fundamental theories such as quantum mechanics and gravitation. While it seems uncontroversial within physics that a 'theory of everything' in this sense of describing all matter and interactions should be possible, even Greene remarks that there is no agreement on further associations with this 'grandiose descriptive term' (p. 16): for a 'staunch reductionist', such a theory would truly describe everything and effectively represent the end of physics, while others, himself included, would highlight that reduction in principle does not imply reduction in practice; they would consider a T.O.E. as but the beginning, namely as 'the firmest foundation on which to build our understanding' (p. 17). Others, still, some of whom I will cite in section three, insist that 'unexpected phenomena' and 'new physical principles' and 'independent laws' would emerge at larger scales (p. 17). 
riving an 'ought' from an 'is'? Isn't it uncontroversial that physics only describes but cannot establish political or ethical norms?

Yet, much of what is written under the label of new materialism argues for the political importance of ontology in the sense I outlined earlier. Their proponents tend to agree on insisting that matter is fundamentally active, agential, vibrant, even vital. In this way, they seek to correct what they interpret as the still-dominant ontology of Descartes and its solidification through Newton's mechanics, which through its success established the paradigm for all modern scientific knowledge. This ontology is dualistic, conceiving matter as passive and inert, and as animated and activated by human subjects - be it directly or in a more complex cultural and linguistic way. ${ }^{2}$ In like manner, the tradition of historical materialism also gets targeted as presupposing the passivity of matter. ${ }^{3}$

Why is it so important for new materialism to overcome this ontology by insisting on the activity of matter? In what sense is it political? To put it very briefly and roughly, the argument is that the dualism of active subject vs passive matter lies at the heart of a host of hierarchical binaries in which one side masters and dominates the other, which has led to the violence of sexism, classism, racism, and the exploitation of nature.

This understanding of the political and its criteria are certainly not new: there is a long tradition of tracing fundamental, political issues to the persistence of hierarchical binaries, and of adopting different positions and strategies in response that seek to overcome the violent consequences of these binaries. Most feminist traditions could be mentioned here, especially ecofeminism, as well as queer theory with its

2 See, e.g., Stacy Alaimo and Susan Hekman, 'Introduction: Emerging Models of Materiality in Feminist Theory', in their co-edited Material Feminisms (Bloomington: Indiana University Press, 2008), pp. 1-19; Diana Coole and Samantha Frost, 'Introducing the New Materialisms', in New Materialisms: Ontology, Agency, and Politics, ed. by Diana Coole and Samantha Frost (Durham, NC: Duke University Press, 2010), pp. 1-43; Jane Bennett, Vibrant Matter: A Political Ecology of Things (Durham, NC: Duke University Press, 2010).

3 See, e.g., Samantha Frost, 'The Implications of the New Materialisms for Feminist Epistemology', in Feminist Epistemology and Philosophy of Science, ed. by Heidi E. Grasswick (Dordrecht: Springer Netherlands, 2011), pp. 69-83 and Simon Choat, 'Science, Agency and Ontology: A Historical-Materialist Response to New Materialism', Political Studies, 66.4 (2018), 1027-42 <https://doi.org/10.1177/0032321717731926>. 
critique of heteronormativity. To use an intellectual shortcut, one can say that what unites otherwise quite diverse positions and problematizes the naturalistic-fallacy argument is the notion of performativity, which undermines the systematic separation of registers: no description or representation of what is is ever neutral. Instead, it is always also performative, productive, and normative.

\section{THE RELEVANCE OF DEACTIVATING THE NORMATIVE POWER OF FUNDAMENTAL ONTOLOGIES}

While I agree that it is important to acknowledge the performative power of ontology, I also think it is important to distinguish different political strategies relating to it. I am thinking, in particular, of different feminist and queer strategies that oppose gender essentialism, that is to say, the dispositive that turns nature into destiny. One primary and influential strategy in these traditions is to distinguish between biological sex and socially constructed gender, and to insist that the norms and categories of gender are contingent and do not result from biology. This strategy could also be described as insisting on a break or cut between ontology and politics, or between what is and what could be - and arguably ought to be - otherwise, and it seems very similar to what I am proposing.

However, there is also the important counter-argument that such a division only serves to veil the social construction of sexual difference and its function of founding and stabilizing a hierarchical gender binary. According to this view - and I am thinking especially of Judith Butler's Gender Trouble and her theory of gender performativity all reference to a pre-discursive ontology is politically suspect. This position abolishes the distinctions between sex and gender, ontology and politics, and the descriptive and the normative, ${ }^{4}$ and replaces them with a continuity. As Butler writes in reference to Monique Wittig: 'sex proves to have been gender from the start.' In other words, ontology is always already politics; 'Ontology is, thus, not a foundation, but a

4 Cf. Butler's reflection on the temptation to distinguish between a descriptive and a normative account of gender in her 1999 preface to Gender Trouble: Feminism and the Subversion of Identity (New York: Routledge, 1999), p. xxi.

5 Ibid., p. 189. 
normative injunction that operates insidiously by installing itself into political discourse as its necessary ground. ${ }^{6}$

In many circles, this kind of argument has made it quasi-taboo to invoke ontology, 'nature', 'being', etc., at least without using inverted commas. And this development is precisely what new materialisms have reacted to. In my reading, these various thinkers share the intuition that refraining from ontological references may only disavow an ontology of inert, passive matter and unwittingly re-enforce it. ${ }^{7}$ They insist on taking matter more seriously and engaging in ontological speculations, asking such questions as, for example, 'What if Culture Was Really Nature All Along?? 8 Of course, with this reversal of Butler's 'sex has been gender from the start', the question becomes how anything can be said or thought about matter without employing discourse. The new materialist move could perhaps be described as follows: Firstly, to highlight the importance of implicit ontological assumptions - in particular, of the opposition between active discourse and passive matter - and the difficulty of avoiding them. ${ }^{9}$ Secondly, to engage with and rework ontology, rather than disavowing it, and thereby seek to improve its politics.

It should be noted that a great deal of the work produced under the banner of the ontological turn - initiated through related but different traditions, especially in science studies and anthropology - is not interested in asserting an ontology that would lie beyond cultural or linguistic construction. Instead, the aim in such work generally seems to be a radicalization of the constructivist impulse and a deflation of

6 Ibid.

7 The mechanism of disavowal that I am invoking here is modelled upon Sigmund Freud's account of fetishism as a disavowal of sexual difference, which involves both a denial of the 'reality' of castration and its acknowledgment through anxiety and the defensive creation of fetishes. Disavowal here produces precisely what it was supposed to avert, namely a split (and in that sense castrated) subject. See the entry 'Disavowal' in Jean Laplanche and Jean-Bertrand Pontalis, The Language of PsychoAnalysis (London: Hogarth Press, 1973), pp. 118-21. From a feminist perspective, a fetishization of women is just as problematic as their identification with an essential lack.

8 Vicki Kirby, 'Natural Convers(at)ions: Or, What If Culture Was Really Nature All Along?', in Material Feminisms, ed. by Alaimo and Hekman, pp. 214-36.

9 Indeed, one might consider it impossible to avoid ontological assumptions, though I wonder whether such a claim would have to be based in pragmatics, anthropology, psychology, or aesthetics rather than logic. 
the normative effect of ontology. This is to be achieved through the identification of a multiplicity of different - that is to say, incompatible but individually equally viable - ontologies, and not merely in philosophical or spiritual belief systems but also in social practices. ${ }^{10}$

I find this strategy promising, and while what I will propose resembles it, I also want to note that it is highly ambiguous. Indeed, proliferating ontological discourses rather than renouncing them increases the risk of unwittingly re-enforcing ontological assumptions through disavowal: ${ }^{11}$ In particular, the view that all ontologies are constructed and mediated by discourse seems to fit well with an ontology of passive matter and active discourse. This is not to say that a pluralization of 'ontologies' - and what has been called 'ontological politics ${ }^{\text {'12 }}$ - necessarily implies such an underlying ontology of matter and discourse, but its redefinition of ontology forecloses the possibility of critically addressing the effect of underlying ontologies - something that was still possible within the strategy of refraining from positive ontological references. ${ }^{13}$

10 Cf. Steve Woolgar and Javier Lezaun, 'The Wrong Bin Bag: A Turn to Ontology in Science and Technology Studies?', Social Studies of Science, 43.3 (2013), pp. 32140 <https://doi.org/10.1177/0306312713488820>; Martin Holbraad, Morten Axel Pedersen, and Eduardo Viveiros de Castro, 'The Politics of Ontology: Anthropological Positions', 2014 <https://culanth.org/fieldsights/the-politics-of-ontologyanthropological-positions> [accessed 26 March 2019]; Christopher Gad, Casper Bruun Jensen, and Brit Ross Winthereik, 'Practical Ontology: Worlds in STS and Anthropology', NatureCulture, 3 (2015), pp. 67-86.

11 Cf. Woolgar and Lezaun's worry that the notion of 'ontological politics' may 'entail commitments that take us beyond the long established deflationary stances of sceptical STS' (p. 336).

12 Cf. Annemarie Mol, 'Ontological Politics. A Word and Some Questions', The Sociological Review, 47.1_suppl (1999), pp. 74-89 <https://doi.org/10.1111/j.1467954X.1999.tb03483.x>, referring to John Law.

13 See, e.g., Astrid Deuber-Mankowsky, 'Das ontologische Debakel oder was heißt: Es gibt Medien?', ZMK Zeitschrift Medien- und Kulturforschung, 8.2 (2017), pp. 157-68, who observes critically that computer-science discourses of 'operational ontologies' avoid and disavow the philosophical question of ontology — what is being? - with the effect that everything, including human beings, is objectified and treated as given data and 'stock' (Bestand). Giorgio Agamben's book What Is Real? (Stanford, CA: Stanford University Press, 2018) is animated by a similar worry, namely that abandoning the properly philosophical question of being means forsaking valuable resources for resisting (neo-)liberal, biopolitical modes of governmentality. But these two thinkers do not employ similar strategies to counter a pluralization of ontologies. While Agamben pushes towards a more properly ontological inquiry, I interpret Deuber-Mankowsky as following the strategy of 'refraining from ontological references' in order to keep the question of ontology open. 
By contrast, the new materialist positions that I focus upon target the ontological level underlying discursive practices. Instead of being interested in deflating ontologies by multiplying them, they propose an alternative ontology: one that conceives of matter as active, vibrant, and even alive, rather than as passive, inert, and dualistically opposed to the activity and agency of human discourse and culture. I am especially interested in the influential argument by Karen Barad, who mobilizes theoretical physics to develop what she calls an 'agential realist ontology. ${ }^{14}$

Although Barad criticizes the excessive power granted to language, she takes no issue with the notion of performativity that, according to Butler, accounts for that power. On the contrary, she extends performativity from language to matter itself. Her neologism 'intra-action' encapsulates much of her argument: this term goes beyond the 'usual "interaction," which presumes the prior existence of independent entities/relata, ${ }^{15}$ and instead allows for the emergence of separate entities. According to Butler, the fact ' $[t]$ hat the gendered body is performative suggests that it has no ontological status apart from the various acts which constitute its reality. ${ }^{16}$ While one might limit this argument to manifestly social categories such as gender, Barad emphasizes than in quantum mechanics the ontological status of elementary entities, such as light or electrons, depends on how their reality is constituted in experimental acts: for instance, depending on the apparatus with which they are observed, they materialize as particles or waves.

The parallels Barad draws between discursive and quantum performativity are striking, compelling, and suggestive. However, they also run the risk of short-circuiting different levels, registers, and scales, thereby creating profound ambiguities and losing a sense of what, in her own account, emerges and comes to matter in between.

On the one hand, expanding performativity extends what I would characterize as top-down constructions, from social discourse all the way down to the sub-atomic scale, while, on the other, it also ends

14 Karen Barad, 'Posthumanist Performativity: Toward an Understanding of How Matter Comes to Matter', Signs: Journal of Women in Culture and Society, 28.3 (2003), pp. 801-31 (p. 811).

15 Barad, 'Posthumanist Performativity', p. 815, emphasis added.

16 Butler, Gender Trouble, p. 173. 
up flipping to its reverse: Rather than refraining from ontological discourse Barad often affirms a particular ontology. Asserting a 'relational ontology', insisting on 'nature's queerness', and affirming an ontology of 'indeterminacy', as she does, certainly avoids many problem associated with essentialism and helps to counteract them. ${ }^{17}$ Still, I would maintain that any ontology, however indeterminate, relational, or processual, becomes problematically normative when one forgets its speculative, constructed, and strategic character and instead just embraces its performativity, which is seen as operating across all scales from the bottom-up, as it were. Among other things that I cannot unfold here, ${ }^{18}$ there is the risk that such an ontology would become unduly extrapolated to suggest that everything is indeterminate and queer, and should and can be recognized and destabilized as such. ${ }^{19}$

Indeed, Barad insists quite emphatically that her account holds for all scales, from the microscopic to the macroscopic and in a precise and literal — rather than merely analogical way — for discourses as much as for matter. ${ }^{20}$ According to my reading, this claim ends up

17 Barad, 'Posthumanist Performativity', pp. 812, 816 and Karen Barad, 'Nature's Queer Performativity', Qui Parle: Literature, Philosophy, Visual Arts, History, 19.2 (2011), pp. 121-58 (pp. 125, 147).

18 See e.g. the contributions by Cornelia Möser and Marianna Poyares in this volume.

19 Such questions of (post)foundationalism in new feminist materialisms are addressed by Katharina Hoppe, 'Eine neue Ontologie des Materiellen? Probleme und Perspektiven neomaterialistischer Feminismen', in Material turn: Feministische Perspektiven auf Materialität und Materialismus, ed. by Christine Löw and others (Leverkusen: Barbara Budrich, 2017). While Hoppe suggests that a 'relational ontology' like Barad's can escape the problem of a normative essentialism, Timothy Morton and Graham Harman warn against over-investing in the political benefits of relational ontologies. See Timothy Morton, 'Treating Objects Like Women: Feminist Ontology and the Question of Essence', in International Perspectives in Feminist Ecocriticism, ed. by Greta Gaard, Simon C. Estok, and Serpil Oppermann (New York: Routledge, 2013), pp. 56-69. Heeding this warning does not imply endorsing Harman's 'speculative realist' alternative, his 'Object Oriented Ontology' (OOO). Rather, I find its critique by Thomas Lemke not only compelling, but - for very similar reasons — also applicable to Barad's Agential Realism, including his argument that 'OOO's promise to break once and for all with subject-object dualism results in a revived form of subjectivism'. See Thomas Lemke, 'Materialism without Matter: The Recurrence of Subjectivism in Object-Oriented Ontology', Distinktion: Journal of Social Theory, 18.2 (2017), pp. 13352 (p. 134) <https://doi.org/10.1080/1600910X.2017.1373686>. In other words, while I argue for the strategic value of speculative ontologies, I also see a need for a critical corrective to their proclaimed realism.

20 Karen Barad, Meeting the Universe Halfway: Quantum Physics and the Entanglement of Matter and Meaning (Durham, NC: Duke University Press, 2007), pp. 24, 86, 110; 'Nature's Queer Performativity', p. 147. See also Elizabeth Stephens, 'Feminism and 
undermining her own sense of 'how matter comes to matter', which requires emergent discontinuities or what she calls 'agential cuts' enacted through intra-action. ${ }^{21}$

I agree that the notion of emergence is key for understanding how matter comes to matter, and also that a cut or discontinuity is important. However, the crucial question is how to relate discontinuity to the notion of emergence, which has gained much currency in recent years but still remains thoroughly ambiguous. ${ }^{22}$ Indeed, the notion of a continuously emerging discontinuity seems inherently contradictory, and requiring it as a condition for something coming to matter risks implying that nothing can actually come to matter and everything is already determined 'from the start' and 'all along', whether through discourse or nature.

Instead, what I would like to suggest is that matter properly comes to matter at any relevant scale to the extent that other scales cease to matter. There is no need to claim any discontinuity here, only a

New Materialism: The Matter of Fluidity', Interalia: A Journal of Queer Studies, 9 (2014), pp. 186-202. I should highlight that Barad's point that quantum phenomena are not necessarily restricted to microscopic scales is well taken if one takes 'scale' only in terms of length scales. Nevertheless, in most interpretations of quantum mechanics (in particular Bohr's), the possibility of describing experiment and its results as classical (rather than quantum) objects is crucial and this requires a large number of accessible degrees of freedom (as can usually be found in macroscopic objects).

21 Cf. Barad, Meeting the Universe Halfway, esp. pp. 175-79. For a critique of Barad's denial of 'scale variance', see Derek Woods, 'Scale Variance and the Concept of Matter', in The New Politics of Materialism: History, Philosophy, Science, ed. by Sarah Ellenzweig and John H. Zammito (Abingdon: Routledge, 2017), pp. 200-24. While I largely agree with his critique, I am sceptical about his insistence of linking 'scale variance' to the emergence of 'jumps and discontinuities' (p. 201) across scales and maintain that physics can only account for a pragmatic sense of emergence. For a helpful and nuanced assessment of Barad's agential realism, stressing the importance of emergent discontinuities as well as exclusions, see Gregory Hollin and others, '(Dis)Entangling Barad: Materialisms and Ethics', Social Studies of Science, 47.6 (2017), pp. 918-41 <https://doi.org/10.1177/0306312717728344>.

22 For entry points into the vast literature on emergence as notion that appeared in latenineteenth biological and evolutionary theories and 're-emerged' in the last quarter of the twentieth century as a 'legitimate' and widely popularized scientific concept in theories of complexity, self-organization, and chaos, see, for example, Peter A. Corning, "The Re-Emergence of "Emergence": A Venerable Concept in Search of a Theory', Complexity, 7.6 (2002), pp. 18-30 <https://doi.org/10.1002/cplx.10043> and the very helpful reader Emergence: Contemporary Readings in Philosophy and Science, ed. by Mark A. Bedau and Paul Humphreys (Cambridge, MA: MIT Press, 2008). 
coming to matter and ceasing to matter, which in turn relies on the possibility of material properties changing with scale. One could speak here of a scale-dependent ontology, as some indeed do, ${ }^{23}$ but as long as the multiple ontologies at different scales remain reducible to an underlying ontology, the normative power of that ontology is bound to remain irresistible.

While breaking with physics in favour of another, more properly philosophical understanding of ontology is always an option, I argue that the desired discontinuity can also be addressed more immanently within physics by considering the limit of infinitely small or infinitely large scales and seeing how incompatible, discontinuously related fundamental ontologies can account for the same finite-scale properties. In the next section, I will give some indications on how thinking with physics in this manner may be helpful in devising strategies to deactivate the normativity of fundamental ontologies, including those of physics itself.

\section{PROPOSITION: A PHYSICS OF EMERGENCE CAN HELP IN DEACTIVATING ONTOLOGICAL NORMATIVITY}

There is something to be learned, I suggest, from the ways in which physics routinely combines and mixes incompatible, discontinuously related ontologies when modelling phenomena emerging at some particular scale, such as the crystallization of liquids, the condensation of vapour into droplets, or other so-called phase transitions. With the phrase 'mixing ontologies' I mean describing matter both in terms of discrete particles moving in a vacuum and in terms of continua of energy, temperature, or some other fluid or field that can flow and propagate waves.

In the late nineteenth century these ontological alternatives were hotly debated and ultimately decided upon in favour of atomism. ${ }^{24}$

23 In addition to Woods, see, for instance, Robert W. Batterman, 'Autonomy and Scales', in Why More Is Different: Philosophical Issues in Condensed Matter Physics and Complex Systems, ed. by Brigitte Falkenburg and Margaret Morrison (Heidelberg: Springer, 2015), pp. 115-35 (p. 133).

24 Debates on atomism, which entangle metaphysics and physics, seem to keep recurring on different time scales even after Immanuel Kant's critical philosophy posits irresolvable antinomies of pure reason. See, for example, Alan Chalmers, 'Atomism from the 
Nonetheless, continuum models, which imply an ontology of continuous, indefinitely divisible fluids rather than discrete atoms, are still in use today and indeed continue to be omnipresent when physics models emergent phenomena such as phase transitions. Of course, the common view is that continuum descriptions are only pragmatic approximations and that continuum properties of matter emerge only in a pragmatic sense at large scales, and are, in principle, reducible to the properties of atoms and their interactions. However, it turns out that simple everyday experiences such as the qualitative difference between phases, the transitions between them, and other thermodynamic phenomena are remarkably hard to grasp or even define without relying on continuum descriptions.

In the late nineteenth century, statistical mechanics was developed to make the reduction of everyday phenomena to an atomistic ontology plausible and to understand how the thermodynamic properties of matter can emerge from mechanics. Perhaps the most important and basic issue at stake here is the so-called second law of thermodynamics, the law of irreversibly increasing entropy, which has been interpreted as defining an arrow of time. The challenge is that the laws of mechanics are reversible - any process going in one direction can also go in the opposite direction - and it would seem logically impossible to derive a directed process, such as a tendency towards equilibrium, from reversible laws. Yet, statistical mechanics shows that if you have enough particles there is an overwhelming probability that the complicated and therefore effectively random movement of microscopic particles will behave as described by thermodynamics and approach equilibrium.

Most physicists are quite satisfied with such an account, which considers all material processes to be reducible in principle but allows for the emergence of new properties — such as irreversibility - in

17th to the 20th Century', in Stanford Encyclopedia of Philosophy, ed. by Edward N. Zalta (Spring 2019 Edition) <https://plato.stanford.edu/archives/spr2019/entries/ atomism-modern/> [accessed 5 May 2020] and Torsten Wilholt, 'When Realism Made a Difference: The Constitution of Matter and Its Conceptual Enigmas in Late 19th Century Physics', Studies in History and Philosophy of Science Part B: Studies in History and Philosophy of Modern Physics, 39.1 (2008), pp. 1-16 <https://doi.org/10. $1016 / \mathrm{j} . \mathrm{shpsb} .2007 .04 .003>$. While physicists may no longer question the reality of atoms, they have also ceased to consider them as elementary and tend rather towards ontologies of continuous fields, strings, or membranes. 
practice. Such a pragmatic sense of emergence is sufficient to justify the use of thermodynamics, and more generally, the relative autonomy of phenomena at higher levels and the respective disciplines studying them, such as chemistry and biology.

However, others observe that this view of 'reducible in principle, but emergent in practice' privileges fundamental physics and undermines other sciences and their objects. In other words, critics have highlighted how a pragmatic sense of emergence introduces no discontinuity or cut, and they worry that the fundamental ontology and its laws continue to dominate everything across all scales.

I take this worry seriously. It corresponds, in effect, to what I have called the normative performativity of ontology, which here takes the form of extending reversibility from the fundamental level to all scales and disregarding a pragmatic emergence of irreversibility. When viewed from a certain perspective, such normativity is irresistible as it seems logically impossible to shift continuously between opposite properties.

In the final quarter of the last century, Ilya Prigogine and Isabelle Stengers were particularly vocal in insisting that thermodynamics should be taken more seriously than a pragmatic approximation of particle mechanics. They argued that change is fundamentally impossible in an ontology of particles obeying deterministic, reversible laws, and time is just an illusion, insofar as the past and future are, in principle, fully determined by the present state. ${ }^{25}$ Within the paradigm

25 To be a little more precise, Prigogine and Stengers highlight in Order Out of Chaos: Man's New Dialogue with Nature (London: Heinemann, 1984) that classical mechanics expresses a 'static view of nature' (p. 11). Seeing that mechanics is all about particles moving in space and time, this claim is counter-intuitive, but their point is that with laws of motion that are both deterministic and reversible, a system's state at any given moment fully determines all states in the future and the past. As Alvin Toffler writes in his foreword, 'there is no evolution, neither to order nor to disorder, the "information" [...] remains constant in time' (p. xxix). The problem with classical physics is, for Prigogine and Stengers, therefore not that it implies or may inspire fatalism - though it certainly does - but rather that it does not allow for any real sense of process, transformation, or becoming. It means ultimately, as they say in reference to Einstein, to 'deny the reality of time as irreversibility, as evolution' (p. 293). Such a sense of time is enabled through irreversible laws of transformation, even if they remain deterministic and involve, for instance, a constant loss of information. In any case, Prigogine and Stengers's insistence on irreversibility through the second law of thermodynamics seems only to further fatalism, which implies neither determinism nor reversibility, but is consistent with the presence of randomness (on which Prigogine and Stengers insist) and even free will. Indeed, the second law is usually associated with entropic 
of particle mechanics, everyday experiences of change, evolution, decay, or anything else that could matter would only be due to our subjective perception, our ignorance of the fundamental details, and to the way we construct the world at our scale. Prigogine and Stengers therefore stress the importance of finding an alternative ontology in which irreversibility and randomness are fundamental. Even if their context is different and their project more thorough, their insistence on acknowledging the fundamental activity and creativity of matter, and their arguments about the far-reaching political and cultural implications of a post-Newtonian ontology, are strikingly similar to new-materialist arguments of this century.

Again, I am suspicious of the foundationalist gesture that insists on the relevance of matter's fundamental ontology and embraces its performative normativity. As an alternative to either refraining from ontology or developing a less damaging one, I propose to deactivate the performative normativity of ontology by redoubling reduction, that is, by showing how the same properties can, as a matter of principle, be reduced to, and therefore also be considered to emerge pragmatically from, radically different ontologies with conflicting performative normativities. In other words, I propose, on the one hand, to accept physics' weak, merely pragmatic sense of emergence, embracing it as the only thing mattering at any given scale; and, on the other hand, I propose to deactivate the normativity conveyed by the claim that emergent properties remain, in principle, reducible through a strategic redoubling: if atoms could only become plausible by demonstrating how observed properties can pragmatically emerge from them at higher scales, then I maintain that, as a matter of principle, the same properties can also emerge in the same pragmatic sense from a radically different ontology of continuous matter.

processes inevitably leading to death, disorder, and decay, and ultimately with the socalled 'heat death of the universe'. However, if fatalism tends to focus on some future event and its imperviousness to whatever happens before, and if standard thermodynamics focuses on describing equilibrium states no matter how they are produced by irreversible processes, the interim is all that matters to Prigogine. In The End of Certainty: Time, Chaos and the New Laws of Nature (New York, NY: Free P, 1996), he recalls the anecdote of a 1946 meeting, in which his interest in nonequilibrium physics was received by a hostile comment that highlighted the transient character of irreversible processes and for which he now would have the repartee: 'But we are all transient. Is it not natural to be interested in our common human condition?' (p. 62). 
Without going into details, let me just highlight that this is not to deny the reality of atoms, but to insist that one can always go to smaller scales and establish well-defined procedures for re-describing atoms as pragmatically emerging from continuum fields. Here discontinuity is neither in emergence or scale but rather between the contrary ontologies that one can posit speculatively, and the point is that this discontinuity becomes increasingly irrelevant as the scale of the fundamental ontology decreases with respect to ours.

Of course, the very notion of a fundamental ontology becomes problematic in this infinite regress to smaller scales, but whereas relational ontologies tend to invoke such a regress - often through the image of 'turtles all the way down'26 — in order to stress a lack of foundation that renders everything unstable, my emphasis lies on the emergence of a remarkable stability and consistency at higher scales. Indeed, the higher scales - which is where matter comes to matter - can be considered autonomous or 'protected' from lower scales. ${ }^{27}$ Conversely, the fundamental ontology becomes increasingly uncertain because nothing can possibly be experienced that would allow for a decision between different ontological options, and therefore the fundamental ontology becomes utterly irrelevant. Rather than an ontology of indeterminacy, I would prefer to speak of an utter indeterminacy of ontology; of an undecidability of ontology rather than an ontology of undecidability.

Fundamental, so-called high-energy physics seems close to the point of showing its own irrelevance, even if it is no doubt premature to speculate over whether the Higgs Boson is the last evidence that can be of some guidance or whether astronomical observations can give some clues. More interesting and certainly more relevant for most of us is what emerges on intermediate scales, from condensed matter physics to chemistry, biology, and geology (to speak only of the natural sciences).

26 See Isabelle Stengers, 'Turtles All the Way Down', in Power and Invention: Situating Science (Minneapolis: University of Minnesota Press, 1997); Donna J. Haraway, When Species Meet (Minneapolis: University of Minnesota Press, 2008), pp. 32-33 and 287.

27 Important references within physics for the kind of argument to which I am alluding here are Philip W. Anderson, 'More Is Different: Broken Symmetry and the Nature of the Hierarchical Structure of Science', Science, 177 (1972), pp. 393-96 and Robert B. Laughlin and David Pines, 'The Theory of Everything', PNAS, 97.1 (2000), pp 28-31. 
If, as I am insisting, the ontologies envisaged by fundamental physics are irrelevant at this scale, my argument that a particle ontology can, in principle, always be re-described in terms of continua (and vice versa) could seem equally irrelevant. My claim is certainly not one in which those working in statistical mechanics, for instance, would be interested, as it would only make the dynamics much more complicated and unmanageable without having any practical advantages. ${ }^{28}$

Conceptually, however, the possibility of such a re-description is significant insofar as large-scale properties, such as the irreversible tendency towards equilibrium, can then be seen as a strict rather than an approximate consequence of the fundamental ontology (which is, as always, only ever posited speculatively). As a consequence, physics' practice of combining descriptions corresponding to incompatible ontologies appears in a different light. Indeed, I would like to point out that the very theory that convinced physicists of the 'reality of atoms' - Einstein's theory of Brownian motion — crucially depends just as much on an atomic description as on a continuum description. ${ }^{29}$ While there is an ingrained habit in physics of considering the continuum as but a large-scale approximation of a more fundamental atomic description, my argument on the double reducibility of all phenomena makes it possible to take the continuum just as seriously and consider atoms as but a way of approximating continuous matter.

I suggest that methodically oscillating between such contrary ontologies and combining them on an equal footing helps to deactivate their normative power and to recognize scale-specific phenomena like Brownian motion as mattering in their own right, that is, not just as proof of atomism but equally as proof of the reality of a continuum, and ultimately also as something 'more' - namely, as something coming

28 Such pragmatic considerations - rather than an obstinate adherence to classical physics - are the main reason that Prigogine's ambitious project of establishing a 'new physics' with an alternative fundamental description (appropriate for phenomena in far-from-equilibrium thermodynamics) remains popular only outside of physics and must be considered a failure within physics, as Stengers also ended up conceding. See Isabelle Stengers, Cosmopolitics, 2 vols (Minneapolis: University of Minnesota Press, 2010-11), II (2011), 'Book v. In the Name of the Arrow of Time: Prigogine's Challenge', pp. 103-204 (pp. 121-22).

29 Cf. Sergio Chibbaro, Lamberto Rondoni, and Angelo Vulpiani, Reductionism, Emergence and Levels of Reality: The Importance of Being Borderline (Cham: Springer, 2014), especially section '3.3 The Paradigmatic Brownian Motion' (pp. 57-62). 
to matter at a specific scale, requiring physics to work through specific combinations of mutually incompatible ontologies. ${ }^{30}$

\section{CONCLUSION}

To conclude, I have argued that the fundamental ontology of matter as theorized by physics is irrelevant at human scales, but that it is politically relevant to address its performative power. I have suggested that this power is due to a seemingly irresistible reductionist attitude that sees in pragmatically emergent properties only the properties of the underlying ontology and not their novel character. In order to deactivate the misleading normativity of ontology, it seems insufficient to highlight that the whole point of physics' reductionist theorizing is to understand how novel properties can emerge from a simple ontology; nor is it effective to refrain from all ontological references or posit an ontology of indeterminacy. Instead, the best political strategy may be to insist on an indeterminacy of ontology, that is, to posit methodically and speculatively mutually incompatible ontologies and work through their consequences in alternation or even conjunction. I suggest that understanding and probing such a methodology in physics may provide helpful models to think with in other domains, even if the relevant ontological questions are quite different, involving not particles and continua, but oppositions such as activity and passivity, matter and language, nature and culture.

According to this view, physics can offer to critical thought not a solid foundation of matter and the world, but rather tools for critique that seem to defy logic and challenge deeply ingrained habits of thought. The political relevance of physics lies in not only showing the irrelevance of its fundamental ontologies, but also in indicating strategies to deactivate their normative ontologies and thereby open spaces for political negotiations.

30 Alluding here to Harman's critique of 'duomining', I suggest to take objects seriously precisely insofar as their modelling within physics requires a double undermining (which is effectively an undermining and an 'overmining'). Cf. Graham Harman, 'Stengers on Emergence', BioSocieties, 9.1 (2014), pp. 99-104 <https://doi.org/10. 1057/biosoc.2013.43> and Graham Harman, 'Agential and Speculative Realism: Remarks on Barad's Ontology', Rhizomes: Cultural Studies in Emerging Knowledge, 30, $2016<$ https://doi.org/10.20415/rhiz/030.e10>. 
Christoph F. E. Holzhey, 'Emergence that Matters and Emergent Irrelevance: On the Political Use of Fundamental Physics', in Materialism and Politics, ed. by Bernardo Bianchi, Emilie Filion-Donato, Marlon Miguel, and Ayşe Yuva, Cultural Inquiry, 20 (Berlin: ICI Berlin Press, 2021), pp. 253-68<https: //doi.org/10.37050/ci-20_14>

\section{REFERENCES}

Agamben, Giorgio, What Is Real? (Stanford, CA: Stanford University Press, 2018)

Alaimo, Stacy, and Susan J. Hekman, 'Introduction: Emerging Models of Materiality in Feminist Theory', in their co-edited Material Feminisms (Bloomington: Indiana University Press, 2008), pp. 1-19

Anderson, Philip W., 'More Is Different: Broken Symmetry and the Nature of the Hierarchical Structure of Science', Science, 177 (1972), pp. 393-96

Barad, Karen, Meeting the Universe Halfway: Quantum Physics and the Entanglement of Matter and Meaning (Durham, NC: Duke University Press, 2007) <https://doi.org/10.1215/ 9780822388128>

'Nature's Queer Performativity', Qui Parle: Literature, Philosophy, Visual Arts, History, 19.2 (2011), pp. 121-58 <https://doi.org/10.5250/quiparle.19.2.0121>

'Posthumanist Performativity: Toward an Understanding of How Matter Comes to Matter', Signs: Journal of Women in Culture and Society, 28.3 (2003), pp. 801-31 <https: //doi.org/10.1086/345321>

Batterman, Robert W., 'Autonomy and Scales', in Why More Is Different: Philosophical Issues in Condensed Matter Physics and Complex Systems, ed. by Brigitte Falkenburg and Margaret Morrison (Heidelberg: Springer, 2015), pp. 115-35 < https://doi.org/10.1007/978-3662-43911-1 7>

Bedau, Mark A., and Paul Humphreys, eds, Emergence: Contemporary Readings in Philosophy and Science (Cambridge, MA: MIT Press, 2008) <https://doi.org/10.7551/mitpress/ 9780262026215.001.0001>

Bennett, Jane, Vibrant Matter: A Political Ecology of Things (Durham, NC: Duke University Press, 2010) <https://doi.org/10.1215/9780822391623>

Butler, Judith, Gender Trouble: Feminism and the Subversion of Identity, with a new pref. by Judith Butler (New York: Routledge, 1999)

Chalmers, Alan, 'Atomism from the 17th to the 20th Century', in Stanford Enyclopedia of Philosophy, ed. by Edward N. Zalta (Spring 2019 Edition) <https://plato.stanford.edu/ archives/spr2019/entries/atomism-modern/> [accessed 5 May 2020]

Chibbaro, Sergio, Lamberto Rondoni, and Angelo Vulpiani, Reductionism, Emergence and Levels of Reality: The Importance of Being Borderline (Cham: Springer, 2014) <https: //doi.org/10.1007/978-3-319-06361-4>

Choat, Simon, 'Science, Agency and Ontology: A Historical-Materialist Response to New Materialism', Political Studies, 66.4 (2018), pp. 1027-42 <https://doi.org/10.1177/ 0032321717731926> 
Coole, Diana, and Samantha Frost, 'Introducing the New Materialisms', in New Materialisms, ed. by Coole and Frost, pp. 1-43 <https://doi.org/10.1215/9780822392996-001> eds, New Materialisms: Ontology, Agency, and Politics (Durham, NC: Duke University Press, 2010) <https://doi.org/10.1215/9780822392996>

Corning, Peter A., 'The Re-Emergence of "Emergence": A Venerable Concept in Search of a Theory', Complexity, 7.6 (2002), pp. 18-30 <https://doi.org/10.1002/cplx.10043>

Deuber-Mankowsky, Astrid, 'Das ontologische Debakel oder was heißt: Es gibt Medien?', ZMK Zeitschrift Medien- und Kulturforschung, 8.2 (2017), pp. 157-68<https://doi.org/10. 28937/1000107979>

Frost, Samantha, 'The Implications of the New Materialisms for Feminist Epistemology', in Feminist Epistemology and Philosophy of Science, ed. by Heidi E. Grasswick (Dordrecht: Springer Netherlands, 2011), pp. 69-83 < https://doi.org/10.1007/978-1-4020-6835$54>$

Gad, Christopher, Casper Bruun Jensen, and Brit Ross Winthereik, 'Practical Ontology: Worlds in STS and Anthropology', NatureCulture, 3 (2015), pp. 67-86

Greene, Brian, The Elegant Universe: Superstrings, Hidden Dimensions, and the Quest for the Ultimate Theory (New York: Vintage Books, 2000)

Haraway, Donna J., When Species Meet (Minneapolis: University of Minnesota Press, 2008)

Harman, Graham, 'Agential and Speculative Realism: Remarks on Barad's Ontology', Rhizomes: Cultural Studies in Emerging Knowledge, 30, 2016 <https://doi.org/10.20415/ rhiz/030.e10>

_ 'Stengers on Emergence', BioSocieties, 9.1 (2014), pp. 99-104<https: / / doi.org/10.1057/ biosoc.2013.43>

Holbraad, Martin, Morten Axel Pedersen, and Eduardo Viveiros de Castro, 'The Politics of Ontology: Anthropological Positions', 2014 <https://culanth.org/fieldsights/thepolitics-of-ontology-anthropological-positions> [accessed 26 March 2019]

Hollin, Gregory, Isla Forsyth, Eva Giraud, and Tracey Potts, '(Dis)Entangling Barad: Materialisms and Ethics', Social Studies of Science, 47.6 (2017), pp. 918-41 <https://doi.org/ $10.1177 / 0306312717728344>$

Hoppe, Katharina, 'Eine neue Ontologie des Materiellen? Probleme und Perspektiven neomaterialistischer Feminismen', in Material turn: Feministische Perspektiven auf Materialität und Materialismus, ed. by Christine Löw, Katharina Volk, Imke Leicht, and Nadja Meisterhans (Leverkusen: Barbara Budrich, 2017), pp. 35-50 <https://doi.org/10.2307/j. ctvddzkq8.6>

Kirby, Vicki, 'Natural Convers(at)ions: Or, What If Culture Was Really Nature All Along?', in Material Feminisms, ed. by Stacy Alaimo and Susan J. Hekman (Bloomington: Indiana University Press, 2008), pp. 214-36

Laughlin, Robert B., and David Pines, 'The Theory of Everything', PNAS, 97.1 (2000), pp. 28 $31<$ https://doi.org/10.1073/pnas.97.1.28>

Lemke, Thomas, 'Materialism without Matter: The Recurrence of Subjectivism in ObjectOriented Ontology', Distinktion: Journal of Social Theory, 18.2 (2017), pp. 133-52 <https: //doi.org/10.1080/1600910X.2017.1373686>

Mol, Annemarie, 'Ontological Politics. A Word and Some Questions', The Sociological Review, 47.1_suppl (1999), pp. 74-89 <https://doi.org/10.1111/j.1467-954X.1999.tb03483. $\mathrm{x}>$

Morton, Timothy, 'Treating Objects Like Women: Feminist Ontology and the Question of Essence', in International Perspectives in Feminist Ecocriticism, ed. by Greta Gaard, Simon C. Estok, and Serpil Oppermann (New York: Routledge, 2013), pp. 56-69 < https://doi. org/10.4324/9780203520840-4>

Möser, Cornelia, 'Materialism, Matter, Matrix, and Mater : Contesting Notions in Feminist and Gender Studies', in Materialism and Politics, ed. by Bernardo Bianchi, Emilie Filion- 
Donato, Marlon Miguel, and Ayşe Yuva, Cultural Inquiry, 20 (Berlin: ICI Berlin Press, 2020), pp. 203-14 <https://doi.org/10.37050/ci-20_11>

Poyares, Marianna, 'Theory's Method?: Political Ethnography and Critical Social Theory', in Materialism and Politics, ed. by Bernardo Bianchi, Emilie Filion-Donato, Marlon Miguel, and Ayşe Yuva, Cultural Inquiry, 20 (Berlin: ICI Berlin Press, 2020), pp. 345-63 < https: //doi.org/10.37050/ci-20_19>

Prigogine, Ilya, The End of Certainty: Time, Chaos and the New Laws of Nature (New York, NY: Free $P, 1996)$

Prigogine, Ilya, and Isabelle Stengers, Order Out of Chaos: Man's New Dialogue with Nature (London: Heinemann, 1984)

Stengers, Isabelle, Cosmopolitics, 2 vols (Minneapolis: University of Minnesota Press, 201011), II (2011), 'Book v. In the Name of the Arrow of Time: Prigogine's Challenge', pp. 103-204

_ 'Turtles All the Way Down', in Power and Invention: Situating Science (Minneapolis: University of Minnesota Press, 1997)

Stephens, Elizabeth, 'Feminism and New Materialism: The Matter of Fluidity', Interalia: A Journal of Queer Studies, 9 (special issue: bodily fluids) (2014), pp. 186-202

Wilholt, Torsten, 'When Realism Made a Difference: The Constitution of Matter and Its Conceptual Enigmas in Late 19th Century Physics', Studies in History and Philosophy of Science Part B: Studies in History and Philosophy of Modern Physics, 39.1 (2008), pp. 1-16 <https://doi.org/10.1016/j.shpsb.2007.04.003>

Woods, Derek, 'Scale Variance and the Concept of Matter', in The New Politics of Materialism: History, Philosophy, Science, ed. by Sarah Ellenzweig and John H. Zammito (Abingdon: Routledge, 2017), pp. 200-24

Woolgar, Steve, and Javier Lezaun, 'The Wrong Bin Bag: A Turn to Ontology in Science and Technology Studies?', Social Studies of Science, 43.3 (2013), pp. 321-40 <https: / doi.org/ $10.1177 / 0306312713488820>$ 